\title{
SÓ É POSSÍVEL HABITAR O QUE SE CONSTRÓI: Uma Compreensão Constitucionalmente Adequada do Direito Fundamental à Moradia no Brasil Contemporâneo
}

http://dx.doi.org/10.21527/2176-6622.2020.53.116-127

Recebido em: 13/12/2019

Modificações solicitadas em: 20/4/2020

Aceito em: 26/4/2020

Débora Laís dos Santos Costa

Mestrado em Constitucionalismo e Democracia na Faculdade de Direito do Sul de Minas. Membro do Grupo de Pesquisa Razão Crítica e Justiça Penal e graduada na Faculdade de Direito do Sul de Minas. Graduanda em Letras português/inglês pelo Centro Universitário do Sul. http://lattes.cnpq.br/8735089534918536.https://orcid. org/0000-0002-4023-953X. deboralais.costa@gmail.com

\section{Edson Vieira da Silva Filho}

Graduação pela Pontifícia Universidade Católica de Minas Gerais, em Belo Horizonte, Mestrado pela Universidade Federal do Paraná. Doutorado pela Estácio de Sá do Rio de Janeiro e Pós-Doutorado pela Universidade do Vale do Rio dos Sinos. Professor do PPGD da Faculdade de Direito do Sul de Minas. http:// lattes.cnpq.br/2225289002355092. https://orcid.org/0000-0002-3997-641X. evsilvaf@globo.com

\section{RESUMO}

Utilizando Heidegger como marco teórico, o trabalho tem o intuito de observar a questão do direito à habitação à luz do constitucionalismo. $O$ déficit de concretização dos direitos humanos em países de modernidade tardia, como o Brasil, especialmente aqueles em que o evento do constitucionalismo contemporâneo se instala com relativo sucesso, torna-se um problema que vai além do político, administrativo e jurídico, esbarrando, antes de mais nada, na questão hermenêutica. Antes de pretender-se a realização do novo, é necessário compreendê-lo em toda a sua extensão para que as questões a ele relativas tenham respostas adequadas. Se o positivismo normativista moderno oferece respostas insuficientes, contraditórias e precárias, há de se buscar o sentido das coisas nelas e em sua mundialidade, único referencial aceitável para que, a partir da compreensão dos entes, cheguem a respostas adequadas. Do chão teórico que faz nascer as novas dimensões jurídicas do morar (muito mais complexo que o simples abrigar) à sua compreensão e aplicação constitucionalmente adequada, há um longo caminho hermenêutico que será abordado neste artigo.

Palavras-chave: Direito de habitação. Constitucionalismo contemporâneo. Direitos humanos. Heidegger.

\section{IT IS ONLY POSSIBLE TO INHABIT WHAT IS BEING BUILT: AN APPROPRIATE CONSTITUTIONALLY UNDERSTANDING OF THE FUNDAMENTAL RIGHT TO HOUSING IN CONTEMPORARY BRAZIL}

\section{ABSTRACT}

Using Heidegger as a theoretical framework, the paper aims to observe the issue of the right to housing in the light of constitutionalism. The shortage of the realization of human rights in late modern countries such as Brazil, especially those in which the event of contemporary constitutionalism sets in relatively success becomes a problem that goes beyond the political, administrative and legal issues, touching, first of all, in hermeneutic issue. Before intent the realization of the new, it must be understood to its full extent so that the questions concerning them have adequate answers. If modern normativist positivism offers insufficient, contradictory and precarious answers, must be sought the meaning of things in them and in their globality, the only acceptable reference for the understanding of ones to arrive at adequate answers. From the theoretical ground that gives rise to the new legal dimensions of housing (more complex than the simple housing) to its constitutionally adequate understanding and application there is a long hermeneutic path that will be addressed in this article.

Keywords: Housing law. Contemporary constitutionalism. Human rights. Heiddeger.

\section{SUMÁRIO}

1 Introdução. 2 Da família consanguínea à propriedade privada: a caminhada para de-morar-se. 3 Habitação na legislação contemporânea brasileira. 4 Só é possível habitar o que se constrói. 5 Conclusão. 6 Referências. 


\section{INTRODUÇÃO}

O presente estudo tem como objeto uma abordagem constitucionalmente adequada, a partir da hermenêutica filosófica heideggeriana, da questão do direito à moradia e sua extensão a partir do constitucionalismo contemporâneo brasileiro que, em 1988, inaugura um modelo de Estado social, plural e democrático, que se projeta para o futuro com a pretensão de ir além das simples regras dinâmicas sociais mas, agora, transformar realidades resgatando promessas não cumpridas da modernidade, como diria Streck (2003).

Desse modo, o trabalho parte da hipótese de que somente a partir de uma leitura constitucionalmente adequada é possivel compreender o habitar enquanto direito social fundamental da sociedade brasileira contemporânea, associando-o a questões como dignidade da pessoa humana e efetividade normativa própria do constitucionalismo contemporâneo adotado no país. A reconstrução hermenêutica apresenta-se como caminho viável (ou condição de possibilidade) para a efetivação e execução de tal direito, o qual elenca o rol das promessas esquecidas pelo projeto moderno.

Assim, buscou-se recriar o chão histórico do conceito de moradia e das transformações pelas quais ele passa no segundo pós-guerra, até sua introdução no modelo jurídico brasileiro. Se a teoria chega há mais de 30 anos à compreensão da extensão do direito à moradia, ainda tardia, o resgate hermenêutico de seu sentido é condição de possibilidade para a concretização do que se espera como essencial para a construção de uma sociedade, que tem como objetivos, constitucionalmente declarados, a redução das desigualdades sociais e erradicação da pobreza.

Em um primeiro momento observou-se a proteção constitucional do direito de morar enquanto habitar, tendo como ponto de partida uma análise da propriedade privada, investigando sua construção histórica a partir do segundo pós-guerra, e social por meio do trabalho de Engels (2002). Em um segundo momento traz este instituto ao direito brasileiro contemporâneo pós-Segunda Guerra Mundial, que, pelas atrocidades acontecidas nos campos de concentração e como contraponto à demanda por uma hermenêutica constitucional adequada à compreensão das novas dimensões do morar e, consequentemente, da concretização constitucional de tal direito fundamental diante do constitucionalismo contemporâneo, começa a construir-se em terrae brasilis em 1988, navegando por águas turbulentas até os dias de hoje.

A partir da crítica hermenêutica do direito de Streck (2014), o presente estudo tem como objetivo buscar uma compreensão adequada do que se propõe como morar e habitar, entes que ganham significações mais amplas e complexas no alvorecer do Brasil do século 21. Por fim, analisará a constitucionalidade do direito brasileiro no que diz respeito à concepção de sentido de morar e habitar.

O instituto da propriedade privada, tal como observa-se na contemporaneidade, constituiu-se depois de certas transformações, as quais a modificou para se adequar à necessidade do homem como indivíduo e ser participante de uma sociedade multicultural. Para se analisar qualquer instrumento benéfico - ou não do Estado, é necessário que se tenha consciência de que todos são construções e, por esse motivo, não despontaram com a humanidade e, sim, a partir de relações artificiais com necessidades únicas.

Percebe-se, então, que a construção do instrumento, propriedade privada, surgiu, de acordo com Engels (2002) - um dos marcos teóricos utilizados no artigo -, no momento em que a família se transformou em monogâmica e, com isso, o homem da família sentiu a necessidade de assegurar seus bens para o herdeiro da família.

Foi indispensável neste contexto que os bens perpetuassem na gens, e isso somente poderia ser feito com a monogamia - uma vez que esta assegurava a fidelidade da mulher e, por esse motivo, sabia-se que o filho dela seria o herdeiro do pai - e com o auxílio de uma entidade com poderes para garantir os direitos na comunidade, que é o Estado.

O fim da Segunda Guerra Mundial trouxe a necessidade de fixar a utilização da propriedade privada à dignidade da pessoa humana e não a nenhum viés econômico, pois os direitos da pessoa passaram a um patamar elevado por conta das barbáries ocorridas nos campos de concentração. 
Depois dessa análise histórica da Segunda Guerra Mundial, observa-se como a propriedade é encarada no direito brasileiro contemporâneo, e, por esse motivo, investiga-se as transformações legislativas que ocorreram por causa da Declaração Universal dos Direitos Humanos, isto é, como a Constituição de 1988 trata a questão da propriedade privada após ratificar a Declaração, fazendo parte dos países-membros da Organização das Nações Unidas.

Ao fim, utilizando-se de Heidegger (1988a, 1988b, e 2013), faz-se uma análise da constitucionalidade do direito brasileiro no âmbito de inferir a conceituação e utilização adequada sob construções de sentido advindas da propriedade privada, como morar e habitar.

O objetivo pretendido foi a pesquisa dos temas que circundam a propriedade privada, limitando-se, porém, a questões quanto ao morar e ao habitar; entretanto, para que seja possível chegar em tal análise, é necessário que se observe as construções históricas que trazem a base para uma investigação mais profunda e, desse modo, sair do lugar comum das pesquisas quanto à propriedade privada.

Foca-se, desse modo, no direito brasileiro contemporâneo e como este observa estas figuras, as quais foram transformando-se durante o tempo, porém sem a adequada fixação de sentido - quanto ao morar e ao habitar - apresentando-se lacunas no direito, o que, por si só, pode vir a trazer questões que prejudicam o direito do proprietário.

Como marcos teóricos, o trabalho utilizou Engels (2002), com A origem da família, propriedade privada e Estado, para construir as análises históricas, e Streck (2011) e Heidegger (1988a, 1988b) para fazer a pesquisa quanto à constitucionalidade do direito à propriedade - moradia e habitação.

\section{DA FAMÍLIA CONSANGUÍNEA À PROPRIEDADE PRIVADA: A CAMINHADA PARA DE-MORAR-SE}

Utilizando-se o livro de Engels (2002), A origem da família, propriedade privada e Estado, observa-se, em um primeiro ponto, a constituição daquilo que é percebido como propriedade privada, sendo indispensável a análise dessa instituição para que se caminhe no texto.

Em um segundo momento, é necessário usar Engels, pois a sociedade, para ser tal como é vista hoje, passou por inúmeras transformações. A partir de tais modificações há a construção dos conceitos de família, propriedade privada e Estado, indispensáveis ao trabalho.

As grandes transformações, que aparecem de tempos em tempos na constituição das sociedades, não podem aparecer como obra do acaso, nem da força, tão-só. A causa que as determina deve ser poderosa, residindo essa causa no próprio homem. Se as leis da sociedade humana não são as mesmas das leis da antigüidade, o motivo está em que algo, no próprio homem, se transformou. Temos, realmente, algo do nosso ser, modificando-se de século a século, ou seja, nossa inteligência. Esta está sempre em movimento, quase sempre em progresso, e, por esse motivo, as nossas instituições e lei são sujeitos a mudanças. O homem não pensa mais hoje do mesmo modo que pensava há vinte e cinco séculos, e é por isso, que ele não se governa mais como antes se governava (COULANGES, 2011, p. 14-15).

Iniciando a investigação na família, percebe-se que, de acordo com as pesquisas de Engels (2002) e Morgan (1877), elas eram concebidas de forma diferente das que se conhece hoje. Assim, as famílias eram consanguíneas (ENGELS, 2002, p. 39), isto é, o vínculo que existia era entre as gerações, ou seja, todos tornavam-se maridos e esposas dentro de sua respectiva geração, e, por esse mesmo motivo, todas eram mães de todas as crianças.

Uma vez que não era possível saber com certeza qual era o pai de cada criança, a árvore genealógica focava na mulher do mesmo jeito que os direitos. Assim, percebe-se que, nesta época da história, os direitos eram maternos.

La originalidad del Derecho materno y su relación con un antiguo nivel cultural no se puede negar, lo que también debe valer para los mistérios, puesto que ambos fenómenos constituyen solamente dos aspectos diferentes de la misma civilización: son siempre hermanos gemelos. Este resultado es tanto más seguro cuanto que no se puede dejar de afirmar que de ambas expresiones de la ginecocracia, la civil y la religiosa, la última sirve como fundamento a la primera. [...]. La preferencia de la madre al padre, de la hija ante el hijo, resulta de la relación de Coré con Deméter, y no, por el contrario, se abstrae ésta de aquélla. $\mathrm{O}$ bien, para ajustarme 
todavía más fielmente a las representaciones de la Antigüedad: de ambos significados del kteís materno, el mistérico-cultual es el originario, el predominante; el civil, jurídico, es la consecuencia. En una concepción completamente material-sensual, el sporium femenino aparece como representación de los misterios demetríacos tanto en su valor físico más profundo como en el opuesto, más elevado, pero también como expresión del Derecho materno en su forma civil, como lo hemos encontrado en el mito licio de Sarpedón (BACHOFEN, 1861, p. 43).

Dentro das gens - "A palavra latina, gens, que Morgan usa para designar esse grupo de consanguíneos [...]" (ENGELS, 2002, p. 85-86) - as mulheres tinham relações com vários homens, pois todos eram seus maridos. Quando estas concebiam filhos havia a certeza da maternidade, considerando que, por causa da poliandria, não se podia identificar quem era o pai de cada criança.

Com o desenvolvimento da sociedade, esta transformou a família consanguínea em punaluana, uma vez que se observou a necessidade de organizar a gens de tal modo que não haveria possibilidade de existir relações entre pais e filhos e entre irmãos.

Foi ocorrendo pouco a pouco, provavelmente começando pela exclusão dos irmãos uterinos (isto é, irmão por parte de mãe), a princípio em casos isolados e depois, gradativamente, como regra geral [...] e acabando pela proibição do matrimônio até entre irmão colaterais [...]. sem dúvida, nas tribos onde esse progresso limitou a reprodução consanguínea, deve ter havido um progresso mais rápido e mais completo que naquelas onde o matrimônio entre irmãos e irmãs continuou sendo uma regra e uma obrigação. Até que ponto se fez sentir a ação desse progresso o demonstra a instituição da gens, nascida diretamente dele e que ultrapassou de muito seus fins iniciais. A gens formou a base da ordem social da maioria, senão da totalidade, dos povos bárbaros do mundo [...] (ENGELS, 2002, p. 40).

A estrutura da sociedade é comunista, posto que havia ajuda mútua e dever de assistir as personagens das tribos. Percebe-se, então, que não há conceituação de propriedade privada, pois cada filho tinha seu espaço na casa de sua respectiva mãe. Caso ocorresse a necessidade de adotar alguma pessoa de uma gens ou tribo diferentes, este fato ocorria de maneira simplificada.

De acordo com Morgan (1877), em seu livro Ancient Society, as mulheres passaram a ter a necessidade de se tornarem monogâmicas e, desse modo, houve outra transformação na sociedade. Em um primeiro momento ocorreu o fim da poliandria, e as mulheres passaram a pertencer apenas a um homem, e, com isso, foram subjugadas a viver apenas no espaço privado das casas.

Em um segundo momento, com a monogamia veio a necessidade de se modificar como o direito era visto, isto é, passou de direito materno para o paterno, e com isso inúmeros direitos das mulheres foram revogados e transformados em direitos paternos; por exemplo, os filhos homens tinham direito de herança dos bens do pai (COULANGES, 2011).

Com essa modificação na construção familiar encontra-se, também, mudanças na sociedade, pois, uma vez que o pai sabia qual filho era seu - pois ele retirou da mulher a possibilidade de se relacionar com outros homens -, ele poderia transferir todos os seus bens para o seu filho e, desse modo, estes continuariam dentro da família.

[...] as riquezas, à medida que iam aumentando, dava, por um lado, ao homem uma posição mais importante que a dada mulher na família, e, por outro lado, faziam com que nascesse nele a ideia de valer-se desta vantagem para modificar, em proveito de seus filhos, a ordem da herança estabelecida. Mas isso não se poderia fazer enquanto permanecesse a filiação segundo o direito materno. Esse direito teria que ser abolido, e o foi. [...]. Bastou decidir simplesmente que, de futuro, os descendentes de um membro masculino permaneceriam na gens, mas os descendentes de um membro feminino sairiam dela, passando a gens de seu pai. Assim, foram abolidos a filiação feminina e o direito hereditário materno, sendo substituídos pela filiação masculina e o direito hereditário paterno (ENGELS, 2002, p. 56-57).

Para que fosse possível tal direito de sucessão era necessário que se construísse a conceituação de propriedade privada, modificando o modo de se observar o domicílio das gens, pois, no início, elas eram firmadas como sociedades comunistas, as quais a propriedade não poderia ser possuída por ninguém. Agora, entretanto, este conceito é reanalisado a fim de se relacionar com o novo contexto social. 
A observação da mudança do conceito de propriedade privada é necessária para o trabalho e só pode ser feita após analisar como a família era constituída, uma vez que ambos os institutos têm relação direta e são indispensáveis para que se entenda a questão central do trabalho, isto é, a investigação quanto ao direito de moradia.

O direito materno cedeu ao direito paterno o seu posto e, por isso, a riqueza privada que surgia abriu a primeira brecha na constituição gentílica. Outra brecha adveio, como consequência natural da primeira: ao introduzir-se o direito paterno, a fortuna de uma rica herdeira que se casa passa ao marido dela, [...]; dessa forma, não apenas se terá por lícito mas ainda por obrigatório, nesse caso, o casamento da jovem núbil no seio da sua gens, para evitar a saída das riquezas (ENGELS, 2002, p. 101).

O direito paterno e a propriedade privada trouxeram a necessidade de constituir uma instituição que conservaria tais construções, pois elas iniciam-se de modo precário e necessitam de um instituto forte que conseguiria parar qualquer violência para com esses novos conceitos. "E essa instituição nasceu. Inventou-se o Estado" (ENGELS, 2002, p. 110).

A instituição Estado proporcionou um amparo imediato para os personagens; entretanto também destruiu as constituições das gens e colocou a propriedade privada na mão dos nobres.

Em Atenas, por exemplo, a destruição das gens iniciou com o desenvolvimento do comércio marítimo, uma vez que essa atividade trouxe a mistura dos personagens das gens, fratrias e tribos (ENGELS, 2002, p. 111-112), e os indivíduos passaram a ocupar terras diferentes, desequilibrando a estrutura gentílica.

It is evident that the failure of gentile institutions to meet the now complicated wants of society originated the movement to withdraw all civil powers form the gents, phratries and tribes, and re-invest them in new constituencies. This movement was gradual, extending through a long period of time, and was embodied in a series of successive experiments by means of which a remedy was sought for existing evils. The coming in of the new system was as gradual as the going out of the old, the two for a part of the time existing side by side (MORGAN, 1877, p. 263).

No governo de Teseu encontra-se a unificação de Atenas, constituindo um conselho geral, o qual solucionava os conflitos colocando o Estado acima das gens. Dentro deste cenário houve a destruição das gens e o desenvolvimento de novas classes - tais como nobres, agricultores e artesãos.

Deve-se observar que a construção de família e de habitação modificou-se em Atenas, pois, em um primeiro momento, as comunidades eram comunistas, e eventualmente constituíram a propriedade privada, a qual, neste ponto histórico, beneficiava a classe mais rica.

Esta classe economicamente mais favorecida determinou o pagamento de impostos para os pequenos agricultores, os quais perdiam suas terras para as hipotecas, ou, então, tinham de pagar para continuar morando em suas propriedades.

[...] os aristocratas de nascimento em Atenas [...] perderam seus privilégios após as reformas de Sólon, [...]. Aristóteles, em sua Constituição dos atenienses, afirma que por muito tempo os nobres e o povo estavam em conflito e que os pobres, suas mulheres e filhos eram escravos dos ricos por conta de suas dívidas. Todas as terras eram propriedade de uns poucos e os devedores insolventes perdiam sua liberdade. Segundo Aristóteles, ainda, Sólon foi o primeiro campeão do povo (GUARINELLO, 2018, p. 83-84).

Percebe-se a importância da propriedade privada como meio de valorização econômica da época, pois a propriedade estava centrada nas mãos de uma classe mais rica. Necessitou-se, assim, que Sólon concebesse leis que impunham a proibição à exigência da hipoteca e à escravidão por endividamento.

[...] obra legislativa de Sólon contemplava normas que iam ao encontro das necessidades do seu tempo, tanto no que diz respeito a problemas sociais [...], como no que se refere a questões relacionadas com a delicada gestão do oikos [...]. Se lhes juntarmos as restantes áreas contempladas nos fragmentos das leis, não deixa de impressionar o alcance do código do velho legislador ateniense; tal facto, além de fornecer um quadro vivo e elucidativo da sociedade ática, ajuda ainda a justificar a fama que, desde a antiguidade, rodeava a figura deste reformador (LEÃO, 2001). 
Desse modo, mesmo não sendo possível estagnar a destruição das gens, a legislação de Sólon conseguiu criar uma codificação que respeitasse a propriedade privada, isto é, o direito do sujeito de de-morar-se.

Assim, com o que foi investigado, observou-se as transformações de uma comunidade que se iniciou amparada no direito materno e em gens, mas modificou-se para que houvesse a certeza da filiação; fazendo isso, foi possível estabelecer a propriedade privada na mão de herdeiros.

É necessário tratar dessa transformação para que se possa entender adequadamente a construção artificial da propriedade privada, passando, no próximo item, para uma análise da legislação que apresenta um devido corte histórico, para que seja possível centrar no tema tratado.

\section{HABITAÇÃO NA LEGISLAÇÃO CONTEMPORÂNEA BRASILEIRA}

Deve-se fazer um corte histórico dentro do artigo para tratar de forma adequada o tema proposto, e, para isso, é indispensável que se foque, neste momento, na Segunda Guerra Mundial, a fim de observar as bases históricas e sociais que levaram à edificação da Constituição de 1988, mesmo que haja uma trajetória entre a construção histórica do primeiro capítulo até a Segunda Guerra Mundial, e depois do final desta guerra em 1945 até a concepção do Estado Democrático de Direito no Brasil.

Desse modo, é necessário perceber que a Segunda Guerra Mundial trouxe modificações significativas para o mundo. Entre a Primeira e a Segunda Guerras Mundiais observa-se um avanço tecnológico, uma mudança na ideologia e o crescimento do nazismo e do fascismo, estabelecendo discursos de ódio que culminaram na morte de 6,5 milhões de judeus, deficientes, homossexuais e ciganos (HOBSBAWM, 1995, p. 57).

Com o fim da Segunda Guerra Mundial, e por causa desta, instrumentos de prevenção de barbáries foram estabelecidos, como a Organização das Nações Unidas, a qual foi criada em 1945 e os documentos influenciados por ela.

O artigo limitar-se-á a tratar do âmbito legislativo, e, por esse motivo, a investigação focará na Declaração Universal dos Direitos Humanos, que se apesenta como primeira carta com o objetivo de ser contracultura dos eventos ocorridos nos campos de concentração. Esta Declaração mostrou-se indispensável no momento em que a Constituição da Alemanha legitimou a perseguição de minorias, e, desse modo, criou campos de concentração constitucionalmente legitimados para torturar aqueles que não tinham características iguais aos dos arianos.

Inegavelmente, a Declaração Universal de 1948 representa a culminância de um processo ético que, iniciado com a Declaração dos direito do Homem e do Cidadão, da Revolução Francesa, levou ao reconhecimento da igualdade essencial de todo ser humano em sua dignidade de pessoa, isto é, como fonte de todos os valores, independentemente das diferenças de raça, cor, sexo, língua, religião, opinião, origem nacional ou social, riqueza, nascimento, ou qualquer outra condição, como se diz em seu artigo II. E esse reconhecimento universal da igualdade humana só foi possível quando, ao término da mais desumanizadora guerra de toda a História, percebeu-se que a idéia de superioridade de uma raça, de uma classe social, de uma cultura ou de uma religião, sobre todas as demais, põe em risco a própria sobrevivência da humanidade (COMPARATO, 2019, p. 2-3).

A Declaração Universal dos Direitos Humanos foi concebida três anos após o final da guerra, em 1948, com o objetivo de assegurar direitos e faculdades imprescindíveis a uma vida plena do indivíduo - independentemente de seu gênero, país, raça e religião -, para que este possa realizar as atividades de sua personalidade física, moral e intelectual (PIOVESAN, 2012).

Observa-se que, desde o preâmbulo, a Declaração preocupa-se em estabelecer uma ordem pública que visa o respeito à dignidade da pessoa humana, a qual passa a se estabelecer em um patamar elevado nas Constituições que serão concebidas a partir da Segunda Guerra Mundial. Em sua redação elenca direitos civis e políticos, contidos nos artigos 30 ao 21, além de direitos sociais, econômicos e culturais, nos artigos 22 a 28.

Encontra-se, no artigo 17 da Declaração Universal dos Direitos Humanos, o direito à propriedade. Percebe-se, assim, que este direito é englobado nos Direitos Humanos e Fundamentais, necessários para que as pessoas possam ter uma vida digna dentro da sociedade moderna. 
[...] são previstos direitos que dizem respeito ao indivíduo em sua relação com grupos sociais nos quais ele participa (o direito à privacidade da vida familiar e o direito ao casamento; o direito à liberdade de movimento no âmbito nacional ou fora dele; o direito à nacionalidade; o direito ao asilo, na hipótese de perseguição; direitos de propriedade e de praticar a religião - arts. 12 a 17) (PIOVESAN, 2012, p. 207).

Com os parâmetros apresentados por esta Declaração, observa-se a necessidade de realizar uma releitura das Constituições, pois estas deveriam resguardar a dignidade da pessoa humana.

Uma vez que as Constituições estabelecidas antes da Segunda Guerra Mundial resguardavam a economia, isto é, preocupava-se em primeiro lugar com a ascensão econômica de uma nação, deixando em segundo patamar os direitos da pessoa humana, foram necessárias algumas mudanças quanto aos direitos fundamentais para que fosse possível juntar-se à Organização das Nações Unidas: "O direito de tornar-se membro das Nações Unidas cabe a todas as nações amantes da paz que aceitarem os compromissos da Carta e que, a critério da Organização, estiverem aptas e dispostas a cumprir tais obrigações" (ONUBR, 2019).

Um exemplo desse fato é o Código Civil Brasileiro de 1916, o qual observava, em primeiro lugar, a propriedade privada, e depois preocupava-se com o homem que a ocupava, posições que foram repensadas após a Segunda Guerra Mundial.

O impasse sobre a definição do conceito de propriedade poderá ser superado com um texto, apresentado ontem pelo Grupo dos 32, que contempla as duas partes em conflito. Essa fórmula estabelece que o direito de propriedade é protegido pelo Estado, subordinado ao bem estar social, sendo que a lei estabelecerá o procedimento para desapropriação pelos poderes públicos nos casos de necessidade, utilidade pública ou interesse social mediante justa e prévia indenização em dinheiro, ressalvados os casos previstos na Constituição. Para a concretização do acordo, ainda há resistência tanto da parte do Centrão como dos progressistas. $O$ texto dessa emenda procura atender a reivindicação da esquerda, que quer ver a propriedade vinculada ao uso social, e aos centristas, que não aceitam que a desapropriação seja feita sem indenização prévia em dinheiro (SILVA, 1988, p. 3).

Desse modo, percebe-se transformações das Constituições Pós-Segunda Guerra, as quais trouxeram para o centro dos direitos a pessoa e suas garantias individuais, necessárias para o novo cenário histórico que se apresenta.

Desde o final da Segunda Guerra Mundial, no plano internacional, e da re-de-mocratização e conseqüente aprovação da Constituição Federal de 1988, no plano interno, verifica-se a elevação dos direitos humanos ao patamar de valor básico da sociedade, do Estado e da comunidade internacional, almejando-se, com isso, o estabelecimento de uma ordem social mais justa (JUBILUT, 2008).

Para o trabalho é interessante focar na Constituição de 1988, posto que ela se apresenta como a Constituição brasileira que possui um maior número de direitos fundamentais e visa à dignidade da pessoa humana, pois traz questões incorporadas da Segunda Guerra Mundial e da ditadura militar de 1964.

Por esse motivo, entendeu-se que o corte histórico poderia ser realizado. Tem-se, aqui, o objetivo de focar na Constituição de 1988, observando, apenas, as características que foram apresentadas pela contracultura que ocorreu após a Segunda Guerra Mundial.

Assim, como meio de barrar qualquer retrocesso dos direitos conquistados, tem-se as cláusulas pétreas apresentadas no artigo $60, \S 4$. Em seu rol taxativo encontram-se direitos e garantias individuais, os quais não podem ser modificados por nenhuma lei ou emenda constitucional.

$\mathrm{O}$ direito à propriedade privada é encontrado no artigo 5 o, inciso $\mathrm{XI}$, o qual expressa a inviolabilidade da casa, tal como apresentado na Declaração Universal dos Direitos Humanos - em seu artigo 17 -, demonstrando a ratificação (UN, 2019) do Brasil para com tal Declaração, uma vez que seus artigos têm validade no território nacional.

Esses direitos são apresentados no rol de direitos fundamentais elencados no artigo 50 da Constituição, mostrando sua importância para o Estado Democrático de Direito e sua força axiológica dentro do conjunto de leis que o constrói. 
Continuando a análise da Constituição, encontra-se, no artigo 170, a propriedade privada sendo tratada como princípio da atividade econômica, isto é, dentro de uma sociedade moderna capitalista a propriedade privada mostra-se essencial, como foi visto no capítulo anterior, uma vez que ambas instituições são historicamente ligadas.

A Constituição não admite, por força dos direitos fundamentais, suprimir a propriedade dos bens e do capital, e, por força deste inciso do artigo vestibular da ordem econômica, resta inconstitucional vedar a circulação da titularidade na esfera privada [...], caracterizando-se, com isso, uma economia de mercado. A nota de destaque, vai para o caráter socializado atribuído ao sistema econômico pelo sistema jurídico, em especial a partir da dignidade da pessoa humana. Princípio expresso logo ao art. 1ㅇ, III, da CF/88 (CANOTILHO et al., 2013, p. 1.798).

Para que a propriedade privada não permaneça apenas em relações econômicas, entretanto, tem-se na Constituição, em seu artigo 50, inciso XXIII - estando, também, no rol de direito fundamentais -, a função social da propriedade privada. Isto significa que a propriedade privada deve trazer benefícios para a sociedade desde moradia até órgãos públicos - como escolas, creches e hospitais -, pois a dignidade da pessoa humana está em um patamar acima, como já dito, e, por esse motivo, a propriedade privada por si só não tem mais espaço em um Estado Democrático de Direito pós-Segunda Guerra Mundial.

Observou-se, desse modo, a construção legislativa da propriedade privada, e, como esta não se limita somente a pertencer ao homem e sim a prestar benefícios a sociedade como um todo, fazendo isso tem relação direta com a Declaração Universal dos Direitos Humanos e seus artigos.

Justamente como consequência de tal compreensão adequada, mesmo que de maneira incipiente e precária, algumas respostas vêm sendo apresentadas, tal como os programas sociais, como Minha Casa Minha Vida, concebido em 2009, que "[...] entregou mais de 4 milhões de imóveis populares no Brasil" (ROSSI, 2019, p. 1), demonstrando que está havendo uma modificação quanto à necessidade de prover domicílio economicamente viável para parte da população que não tem meios.

\section{SÓ É POSSÍVEL HABITAR O QUE SE CONSTRÓI}

De há muito Streck (2011) promove uma discussão acerca do que ele chama de baixo grau de constitucionalidade no Brasil contemporâneo. Streck refere-se à incapacidade crônica que se tem no Brasil contemporâneo de satisfazer o alto grau de demandas que exsurgem do constitucionalismo contemporâneo brasileiro, em oposição à diminuta capacidade de satisfazê-las por intermédio do "[...] Estado, no seu modelo alcunhado de Democrático de Direito, plus normativo em relação aos modelos que o antecederam" (STRECK, 2011, p. 47).

A explicação e consequentes caminhos para responder à questão do déficit constitucional, feita por Streck (2014), se dá a partir da crítica hermenêutica do direito e tem como pano de fundo a hermenêutica filosófica heideggeriana no que diz respeito à construção de sentidos, perdidos nas leituras inadequadas da Constituição.

Em suma, Streck (2011) reclama por uma nova teoria das fontes, das normas e hermenêutica para uma aproximação, compreensão e aplicação constitucional adequada. Ou seja, um novo olhar para a compreensão da atual hermenêutica e uma teoria atualizada. Só é possível habitar o que se constrói.

O texto constitucional é expresso ao proteger/promover o direito fundamental à habitação, mas trata as expressões habitar e morar como se fossem sinônimas e fala de maneira esparsa e pouco sistêmica de competências para a promoção do direito de se habitar.

Esquece daquele que habita e do que constrói quando se edifica uma moradia, das raízes e dos fins das coisas como seres-no-mundo (HEIDEGGER, 1988b, p. 83), mas, afinal, para se dar efetividade a algo, ao direito fundamental de habitar, por exemplo, é preciso ter-se uma mínima noção acerca daquilo que se pretende promover, resgatando as promessas não cumpridas da modernidade. Assim,

Se a Constituição assume uma feição de resgate das promessas (incumpridas) da modernidade (esse é o modelo da revolução copernicana que atravessou o direito no século XX), a construção das condições para a obtenção de respostas corretas nada mais é do que a construção das condições para que se alcance respostas adequadas à Constituição (HEIDEGGER, 1988b, p. 114). 
Tem-se posto de maneira expressa no texto constitucional o que se compreende com morar/habitar/ construir, enquanto direitos fundamentais (grifos nossos):

São direitos sociais

Art. 60 São direitos sociais a educação, a saúde, a alimentação, o trabalho, a moradia, o transporte, o lazer, a segurança, a previdência social, a proteção à maternidade e à infância, a assistência aos desamparados, na forma desta Constituição. IV - Salário mínimo, fixado em lei, nacionalmente unificado, capaz de atender a suas necessidades vitais básicas e às de sua família com moradia, alimentação, educação, saúde, lazer, vestuário, higiene, transporte e previdência social, com reajustes periódicos que lhe preservem o poder aquisitivo, sendo vedada sua vinculação para qualquer fim;

Art. 21. Compete à União: XX - Instituir diretrizes para o desenvolvimento urbano, inclusive habitação, saneamento básico e transportes urbanos;

Art. 23. É competência comum da União, dos Estados, do Distrito Federal e dos Municípios: IX - Promover programas de construção de moradias e a melhoria das condições habitacionais e de saneamento básico;

Art. 79. É instituído, para vigorar até o ano de 2010, no âmbito do Poder Executivo Federal, o Fundo de Combate e Erradicação da Pobreza, a ser regulado por lei complementar com o objetivo de viabilizar a todos os brasileiros acesso a níveis dignos de subsistência, cujos recursos serão aplicados em ações suplementares de nutrição, habitação, educação, saúde, reforço de renda familiar e outros programas de relevante interesse social voltados para melhoria da qualidade de vida.

Art. 186. A função social é cumprida quando a propriedade rural atende, simultaneamente, segundo critérios e graus de exigência estabelecidos em lei, aos seguintes requisitos: VIII - A habitação para o trabalhador rural.

Art. 243. As propriedades rurais e urbanas de qualquer região do País onde forem localizadas culturas ilegais de plantas psicotrópicas ou a exploração de trabalho escravo na forma da lei serão expropriadas e destinadas à reforma agrária e a programas de habitação popular, sem qualquer indenização ao proprietário e sem prejuízo de outras sanções previstas em lei, observado, no que couber, o disposto no art. 5‥

Para Heidegger, construir é, simultaneamente, meio, e também é habitar (HEIDEGGER, 1988a, p. 126127). O habitar extrai-se a partir da linguagem (WITTGENSTEIN, 2001), condição de possibilidade de se compreender o ser. Quando se perde a linguagem como se vê na Constituição, de que habitar e morar, construir e morar confundem-se, perde-se a noção daquilo que se tem de autêntico no ser, liberando-o de sua mundialidade intramundana (HEIDEGGER, 1988b, p. 135). O homem é à medida que habita (HEIDEGGER, 1988a, p. 127).

Habitar é mais do que morar, que ocupar uma residência, um lugar no mundo. Em Heidegger (1988a) tem-se que o motorista habita as estradas, pelas quais passa parte da sua existência, pois nelas realiza seu modo de ser, realiza o ser/sal da terra. Nela completa-se de diversos modos. A experiência de habitar constitui ao ser do homem (HEIDEGGER, 1988a, p. 128-130), uma vez que "O ser-aí não se encontra na determinação do definível, mas na cotidianidade e em sua historicidade" (HEIDEGGER, 2013, p. 99).

Deve-se perceber que a sociedade parte de uma construção de tempo e espaço, e, assim, analisa-se que de-morar-se sobre a terra é edificar sentidos de sua comunidade (HEIGEGGER, 1988a). Acontece que o homem, diante da angústia, modo de existência humana, encontra-se em uma encruzilhada no seu fardo de interpretar: fugir para o esquecimento retornando ao seu cotidiano ou superar a angústia, transcendendo sobre o mundo, ou seja, atribuindo sentido ao ser. O homem, assim, ser-para a morte, angustia-se e, na angústia, interpreta (CHAUÍ, 1999, p. 8).

Os homens, capazes da morte como morte, somente ele morre continuamente enquanto permanecer sobre a terra, sob o céu e perante os deuses (HEIDEGGER, 1988a, p. 129), ocupando seu lugar na quadratura; como parte, não como senhores tampouco como objetos. Salvando a terra, acolhendo o céu, aguardando os deuses e conduzindo os mortais (HEIDEGGER, 1988a, 129-131).

Habitar é abrigar a quadratura no vigor de sua essência. Habitar é bem mais do que de-morar sobre a terra, sob o céu, perante os deuses, é de-morar-se naquilo junto a que os mortais se demoram: as coisas.

Não se promove o que não se compreende. As palavras do texto constitucional estão ressecadas, empobrecidas por seu uso apartado da história, das tensões e das compreensões do habitar, do morar, do promover o construir de moradas que edificam sentido, que transformem realidades a partir da proposta constitucional adequadamente compreendida. 
O compreender é o estar aberto à mundialidade dos entes intramundanos, como Heidegger afirma. A determinação da significância encontra-se no caráter significativo de cada caso e mostra-se em duas caracterizações: no caráter do dado e na manifestação prévia do mundo compartilhado. Continua afirmando que o mostrar-se de maneira mundana vem ao encontro em si mesmo enquanto o ente que: serve para algo, se usa para alguma coisa, não serve mais para tais fatos, levando ao seu ser-aí-para-isso (HEIDEGGER, 2013, p. 98).

Assim, pode-se afirmar que a compreensão da extensão do significado do ente, habitar, e de seu trato adequado, demanda a compreensão do seu ser em uma determinada racionalidade (mundialidade ou a partir de horizontes autênticos) do texto constitucional. Em um Estado Social, Democrático e de Direito, o qual a Constituição, segundo Streck (2011), (ainda) constitui, há que se compreender, dentro do Estado, até o momento com fortes traços da modernidade, se dá entre o apofântico e o hermenêutico, em uma circularidade que causa estranhamentos, em virtude do que demanda novas formas de compreender os mesmos entes a partir de seus novos modos de ser-aí. Logo, a Constituição acaba por se tornar, neste modelo de Estado, horizonte de compreensão autêntico.

Assim, o objetivo do trabalho é propor limites e possibilidades da extensão da expressão habitação e o conceito de moradia, não só em um delimitado tempo e espaço, o Brasil de hoje, mas em um contexto jurídico constitucional que se alcança a partir da crítica hermenêutica do direito de Streck (2014), resgatando o mundo concreto e a compreensão das coisas a partir de sua mundialidade.

Em suma, permitir que os direitos fundamentais tracem os contornos aduados para o conceito morar e habitar e, consequentemente, possibilitar que o déficit que diz respeito a eles seja sindicado, dentro dos parâmetros de uma Constituição plural, tolerante, includente e voltada para a obtenção de fins sociais.

Partindo-se da premissa de que não se pode falar qualquer coisa sobre qualquer coisa, o sentido de morar como direito fundamental constitucionalmente protegido e dignamente delineado, deve nortear as respostas do Estado Democrático de Direito após as transformações que ocorreram com a modernidade.

Somente a compreensão constitucionalmente adequada pela via da crítica hermenêutica do direito é capaz de dar respostas livres do decisionismo moderno e que de há muito torna o direito escravo da filosofia da consciência e objeto de manipulação a-decisionista.

\section{CONCLUSÃO}

As transformações da sociedade também se apresentaram no âmbito de como o homem médio analisa construções como família, propriedade privada e Estado. Por esse motivo, a contextualização histórica de tais instituições foi necessária para que se tratasse do tema de modo mais aprofundado.

Dessa maneira, observa-se que, com a mudança da estruturação da família - isto é, passando de poliandria para monogamia - e os direitos que a circundavam - do direito materno para o direito paterno -, houve a necessidade de se apresentar a base de um novo instituto para a sociedade da época, a propriedade privada, a qual trouxe consigo a noção de herança e de bens privados, ambos pertencentes aos homens da família.

Para que fosse possível resguardar tais direitos adquiridos constituiu-se, de forma artificial, um ente com poderes hierarquicamente mais altos do que os outros, o Estado. Por esse motivo, o Estado desponta como meio para assegurar os direitos obtidos na passagem do direito materno ao paterno.

Com as modificações da sociedade moderna encontram-se outros tipos de necessidades a serem resguardadas pelo Estado, como a dignidade da pessoa humana, questão importante após a Segunda Guerra Mundial. Uma vez que o foco de anseios se modifica, é dever do Estado proteger os novos direitos requeridos pela sociedade que está em constante transformação.

Houve, então, a necessidade de relacionar as Constituições com os novos anseios da população, as quais se viram negligenciadas pelo Estado. Assim, em 1945, criou-se a Organização das Nações Unidas, que promulgou, três anos depois, a Declaração Universal dos Direitos Humanos, a qual concebia a dignidade da pessoa humana a um patamar mais alto e trouxe consigo outros direitos, sendo um deles o direito à propriedade privada.

Percebe-se que não se trata da propriedade privada como meio de reter bens dentro de uma mesma família, e sim como necessidade de que o homem deve ter onde morar para que possa usufruir de uma vida digna. 
Dentro da Constituição de 1988, a modificação do conceito de propriedade privada mostra-se no momento em que é indispensável que ela tenha função social, isto é, não é possível possuir um terreno, o qual não abriga uma família - ou indivíduo - ou traz algum tipo de benefício para a sociedade, como um hospital.

Essa reivindicação da legislação retira a propriedade privada do âmbito econômico, ou seja, da esfera estritamente capitalista da detenção do terreno, e passa para o anseio da família de viver dignamente dentro de uma casa, demonstrando que a Constituição se volta às pretensões do homem médio e de sua dignidade.

Percebe-se, entretanto, que a constitucionalidade do direito brasileiro não foi bem-sucedida no momento em que não apresentou uma construção de sentido quanto à moradia e habitação, uma vez que ambos institutos estão no Código Civil e trazem questões jurídicas diferentes.

Para o Direito, o ato de morar ou habitar em uma propriedade privada aborda tópicos diferentes, pois, por exemplo, no Código Civil encontram-se direitos e deveres a serem esclarecidos para o possuidor, o proprietário e quem tem o domínio.

A Constituição de 1988 peca por sua modernidade tardia e não consegue alcançar as leis infraconstitucionais a fim de impor a dignidade da pessoa humana. Desse modo, a sua constitucionalidade é um fato que pode ser analisado quando existem lacunas de sentido em questões como moradia e habitação, instituições que são discutidas desde que o ser humano torna-se sedentário e forma a família tal como é conhecida atualmente.

\section{REFERÊNCIAS}

BACHOFEN, J. J. El Matriarcado: una investigación sobre la ginecocracia en el mundo antiguo segun su naturaleza religiosa y juridica. Tradução María del Mar Llinares García. Madrid: Akal, 1861.

CANOTILHO, J. J. Gomes; MENDES, Gilmar Ferreira; SARLET, Ingo Wolfgang; STRECK, Lenio Luiz (coord.). Comentários à Constituição do Brasil. São Paulo: Saraiva, 2013.

CHAUÍ, Marilena de Souza. Apresentação - vida e obra de Martin Heidegger. In: Martin Heidegger: vida e obra. São Paulo: Nova Cultural, 1999.

COMPARATO, Fábio Konder. A declaração universal dos direitos humanos. Disponível em: http://www.dhnet.org.br/direitos/ deconu/a_pdf/comparato_hist_dudh.pdf. Acesso em: 5 jan. 2019.

COULANGES, Fustel de. A cidade antiga: estudo sobre o culto, o direito e as instituições da Grécia e de Roma. Tradução J. Cretella Jr. e Agnes Cretella. 2. ed. São Paulo: Revista dos Tribunais, 2011.

ENGELS, Friedrich. A origem da família, da propriedade privada e do Estado. Tradução Ruth M. Klaus. São Paulo: Centauro, 2002.

GUARINELLO, Noberto Luiz. História antiga. São Paulo: Contexto, 2018.

HEIDEGGER, Martin. Construir, habitar, pensar. In: Ensaios e conferências. Trad. Emmanuel Carneiro Leão et al. 5. ed. Petópolis: Vozes; Editora Universitária São Francisco, 1988a.

HEIDEGGER, Martin. Ontologia: hermenêutica da facticidade. Tradução Renato Kirchner. 2. ed. Petrópolis: Vozes, 2013. HEIDEGGER, Martin. Ser e tempo. Trad. Márcia de Sá Cavalcante. Petrópolis: Vozes, 1988b.

HOBSBAWM, Eric. Era dos extremos: o breve século XX. 2. ed. São Paulo: Companhia das Letras, 1995.

HOBSBAWM, Eric. Tempos faturados: cultura e sociedade no século XX. Tradução Berilo Vargas. São Paulo: Companhia das Letras, 2013.

JUBILUT, Liliana Lyra. O estabelecimento de uma ordem social mais justa a partir dos direitos humanos: novos paradigmas e novos sujeitos. Revista da Faculdade de Direito do Sul de Minas, Minas Gerais, v. especial, p. 55-68, 16 mar. 2008.

LEÃO, Delfim F. Matrimónio, amor e sexo na legislação de Sólon. Hvmanitas, Coimbra, v. LIII, p. 113-133, 2001.

MORGAN, Lewis H. Acient Society. Chicago: Charles H. Kerr \& Company, 1877.

ONUBR. ONU Brasil. Países-membros da ONU. Disponível em: https://nacoesunidas.org/conheca/paises-membros/. Acesso em: 12 mar. 2019.

PIOVESAN, Flávia. Direitos humanos e o Direito Constitucional Internacional. 13. ed. São Paulo: Saraiva, 2012.

ROSSI, Amanda. Sua casa sua dívida. Revista Piauí, 18 nov. 2019. Disponível em: https://piaui.folha.uol.com.br/sua-casa-sua-divida/. Acesso em: 23 abr. 2020.

SILVA, Aldon. Grupo tem proposta que permite acordo sobre a propriedade. Jornal de Brasília, Brasília, p. 3, 6 fev. 1988. 
STRECK, Lenio Luiz. Jurisdição constitucional e hermenêutica: perspectivas e possibildiades de concretização dos direitos fundamentais-sociais no Brasil. Novos Estudos Jurídicos, v. 8, n. 2, p. 257-301, maio/ago. 2003. Disponível em: https://siaiap32. univali.br/seer/index.php/nej/article/view/336/280. Acesso em: 21 abr. 2020.

STRECK, Lenio Luiz. Lições de crítica hermenêutica do Direito. Porto Alegre: Livraria do Advogado, 2014.

STRECK, Lenio Luiz. Verdade e consenso: Constituição, hermenêutica e teorias discursivas. Da possibilidade à necessidade de respostas corretas em direito. 4. ed. rev. e ampl. Rio de Janeiro: Lúmen Júris, 2011.

UN. Charter of the United Nations and Statute of the International Court of Justice. Disponível em: https://treaties.un.org/doc/ Publication/UNTS/No\%20Volume/Part/un_charter.pdf. Acesso em: 12 mar. 2019.

WITTGENSTEIN, Ludwig. Tractatus lógico-philosophicus. Trad. Luiz Henrique Lopes dos Santos. São Paulo: Edusp, 2001. 